In cases, however, where chloroform has been swallowed, it is not only the immediate effects of the drug that we have to fear, and this is well exemplified in the instance of the patient already quoted, who died from the subsequent inflammation set up. Fortunately, in the present case, the symptoms of the secondary danger were never very severe, and were easily controlled by mild remedies.

Royal Infirmary, Edinburgh, 1856.

ON

\section{SECONDARY SYPHILIS TREATED BY A NEW PREPARATION OF IODINE, \&c.}

By J. C. CHRLSTOPHERS, EsQ., F.R.C.S.

THE good "results ordinarily obtained from treating cases of secondary syphilis by the various officinal preparations of iodine are universally known, yet there are cases which resist their influence, and there are constitutions which rebel under their administration. The object of this paper is to introduce to your notice a new preparation, perhaps a new compound, which, combining the good effects to be derived from iodine, is devoid of its disadvantages-a preparation which, in my hands, has proved valuable in curing cases of secondary syphilis which had previously resisted the beneficial action of iodine in all its usual combinations and forms-a preparation, moreover, which does not produce the evil effects of iodine in those constitutions with which that substance is known to disagree.

My experience of the action of this remedy is limited to cases of secondary syphilis; but in the hands of some other surgeons, I am told, it has been found efficacious in cases of scrofula, anæmia, and in the furunculoid plague which has infested this city during the last three or four years.

To Mr. Hockin, the chemist, in Duke-street, (who manufactures it under a patent granted to $M$. Dupont,) I am indebted for my knowledge of this preparation, and for its formula. There are, indeed, two preparations: the one (that which have found so useful in treating cases of secondary syphilis) he names "liquor cinchonæ hydriodatus;" the other, (that which has been found useful in treating boils, anæmia and scrofula, "liquor cinchonæ hydriodatus cum ferro." The former contains in one fluid drachm of liquor, twelve grains of cinchonæ flav., and one grain and a half of iodine, in the form of hydriodic acid. The latter contains, in addition to the former ingredients, one grain of protoxide of iron in each fluid drachm of the liquor. These preparations are produced by exhausting the powdered bark with an aqueous solution of hydriodic acid; then with water, and the liquor is subsequently evaporated to the above bulk.

The circumstance that the iron compound ever remains in a state of proto-salt, and that the liquor never, either by time or by exposure, becomes inky, through the action of the tannic principles in the bark, goes to show that there is here something more than a mere mixing of ingredients, and that some new combination of iodine, the cinchona alkaloids, and the peculiar tannic principle exists in it, which the fact corroborates, that the same materials act differently when used singly, together, or when otherwise combined.

The dose in which I have prescribed these preparations varies from one drachm to three drachms of "the liquor cinchonæ hydriodatus," and from fifteen minims to two drachms of "the liquor cinchonæ hydriodatus cum ferro;" and in these doses I have not found any of the evil effects arise which smaller doses of other preparations of iodine have been known to produce.

I must not omit to say, (inasmuch as I attach much importance to its use,) that in some of the successful cases treated by means of the preparation described, I have also employed the hot-air apparatus, in order to produce profuse sweating, and always with marked good effect. Indeed, I do not know a more potent remedy for intractable and inveterate cases of secondary syphilis than this is.

The ancients recognised the great advantage of sweating their patients when treating them for this disease, and most of the authors of an early period prescribe it as a remedy, and some of them give elaborate directions for producing and for prolonging its effects. They describe the sweating by medicines, sweating in bed, sweating in a hot-house (whenever it 160 can be procured, and sweating by labour, and either of these processes they designated the "sweating course."

It has occurred to me to find that it is far more difficult to cure secondary syphilis in the higher than in the labouring classes, and I have thought that the daily occupation of the latter, whereby the skin is forced into constant action, may in some measure account for it.

Opium was at one time considered to be a specific for syphilis. I have found it useful, and most so in those cases in which it produced free perspiration - its very usual effect.

The use of the hot-air bath is impeded by the thought that it entails a difficult and complicated apparatus, and that it cannot be used by the patient when at home. It is not so. Few things are more simple, easier of access, or less costly than it, and the patient can be submitted to its action in his own bed. There are many forms: one of the most simple was employed by Dr. Wilson, in the Middlesex Hospital, with good effect; another by Mr. Kurtz, a chemist, at Liverpool. The former was employed for sweating only; the latter for sweating, and for the administration of iodine and sulphur.

York-place, Portman-square, A ugust, 1856.

AN EASY AND EFFICIENT MODE OF TREATING INVERSION OF THE NAIL OF THE GREAT TOE.

\section{BX J. BROKE GALLWAY,} SURGEON ROYAL ARTILLERY.

(Communicated by Dr. ANDREw Siritr.)

A GOoD deal has been enunciated from time to time of late years upon the most legitimate line of practice necessitated by the frequency of an affection of no very dignified pretension in the catalogue of chirurgical woes, but, for all that, possessing strong claims to our notice from the suffering occasioned by its presence, and still more for that attendant upon the means in common use for its relief-in-growing of the nail of the great toe.

In systematic works on surgery, the acknowledged line of practice for this condition is the barbarous rule of forcing a sharp instrument from the free edge up to the root of the nail and tearing the latter away by a process of evulsion - an operation which is certainly deprived of much of its suffering by chloroform, though still the opprobrium of surgery to the eye and the imagination. The periodical press has teemed with modifications of and improvements upon this practice.

I have found the following little expedient attended with but trifling pain, while it offers a most efficient remedy for the evil :-With a fine and well-tempered file, let a vertical incision be carried down to the matrix, from the root to the free margin of the nail, a few lines from the lateral border, according to the degree and extent of the inversion. This part of the step can be performed by the patient himself, and at his own leisure, which in private life has the advantage of robbing the operation of much of its terrors. It is easily effected, and, I need not say, painless. When thus prepared, the surgeon should gently seize the divided edge of the smaller section with a pair of broad-bladed dissecting forceps, and with an infinitesimal amount of tractile and of slightly jerking force tear the offending portion of the nail from its bed and lateral connexions. It is really a very neat operation, and most satisfactory in its results. It should be repeated at the opposite border of the nail, supposing both lateral margins to be inverted.

By this little expedient I have lately resuscitated a poor fellow who had become quite lame in both feet from this condition.

Corfu, July, 1856.

REPORTS OF

\section{CASES ILLUSTRATIVE OF IMPORTANT POINTS IN MIDWIFERY.}

By J. M. W I N N, M.D., L. R. C.P., SENIOR PHYSTCIAY TO THE METROPOLITAY DISPENSARY, ETE,

IT will be readily admitted, by every practical man, that selections of important cases, concisely and judiciously narrated, have thrown more light on the treatment of disease than all the combined labours of the chemist and mieroscopist. 